\title{
Computerized Assessment of Food Preferences in Adolescents in the Stimulus Equivalence Paradigm
}

\author{
Gisele Straatmann \\ Sebastião Sousa Almeida ${ }^{1}$ \\ Departamento de Psicologia da Universidade de São Paulo, Ribeirão Preto, \\ São Paulo, Brasil \\ Julio C. de Rose \\ Departamento de Psicologia da Universidade Federal de São Carlos, São Carlos, \\ São Paulo, Brasil
}

\begin{abstract}
In Experiment 1, 71 participants were trained to match three pictures of facial expressions (one that expressed happiness and two that expressed emotional neutrality) to three abstract line drawings and match three healthy food names to the abstract line drawings. The participants were then tested to verify equivalence between facial expressions, abstract pictures, and foods. They were required to rate the foods for pleasantness at the beginning and end of the experiment. The experiment had three different experimental groups that differed only in the amount of training. The foods that were equivalent to the happy and neutral female faces received more positive evaluations than the foods that were equivalent to the neutral male face; however, the data presented high variability. In Experiment 2, schematic faces and fictitious food names were used in a delayed matching-to-sample procedure. The food that was equivalent to the happy face was evaluated as more pleasant, and the food that was equivalent to the sad face was evaluated as less pleasant.
\end{abstract}

Keywords: Stimulus equivalence, transfer of function, facial expressions, food preference.

\section{Avaliação computadorizada das Preferências Alimentares em Adolescentes no Paradigma de Equivalência de Estímulos}

\section{Resumo}

No Experimento 1 foram ensinadas relações entre três expressões faciais (uma de alegria e duas neutras) a três desenhos abstratos e em seguida ensinado a relação de três nomes de alimentos saudáveis aos três desenhos abstratos para 71 participantes. Depois de passar pelo treino das relações, os participantes foram, então, testados para verificar a equivalência entre as expressões faciais, as imagens abstratas e os alimentos. A avaliação da preferência alimentar foi realizada no início e no final do experimento. $\mathrm{O}$ experimento teve três diferentes grupos experimentais que diferiam apenas na quantidade de treinamen-

\footnotetext{
Mailing address: Departamento de Psicologia, Faculdade de Filosofia, Ciências e Letras de Ribeirão Preto, Universidade de São Paulo, Av. dos Bandeirantes, 3900, Ribeirão Preto, SP, Brasil 1040-901. E-mail: giselestr@gmail.com, sebasalm@usp.br and juliocderose@yahoo.com

This research was supported by FAPESP (State of São Paulo Research Foundation; grant no. 05/57745). Preparation of the manuscript was supported by FAPESP/Programa de Apoio a Núcleos de Excelência (PRONEX; grant no. 03/09928-4) and Instituto Nacional de Ciência e Tecnologia: Comportamento, Cognição e Ensino. The second and third authors have research fellowships from Conselho Nacional de Desenvolvimento Científico e Tecnológico (CNPq).
} 
to das relações. Os alimentos equivalentes às expressões faciais de alegria e neutra feminina tiveram avaliações mais positivas do que os alimentos equivalentes à face neutra masculina, no entanto, os dados apresentaram grande variabilidade. No Experimento 2 expressões faciais esquemáticas e nomes fictícios de alimentos foram usados em um procedimento de emparelhamento com o modelo com atraso. $\mathrm{O}$ alimento treinado com a face feliz foi avaliado como mais agradável e o relacionado a uma face triste foi avaliado como menos agradável.

Palavras-chave: Equivalência de estímulos, transferência de função, expressões faciais, preferência alimentar.

\section{Evaluación Computarizada de las Preferencias Alimentarias de los Adolescentes en lo Paradigma de la Equivalencia de Estímulo}

\section{Resumen}

En el experimento 1 se enseñaban las relaciones entre los tres expresiones faciales (una de alegría y neutral dos) para tres diseños abstractos y luego enseñó la relación de los tres nombres de los alimentos saludables en tres diseños abstractos a 71 participantes. Después de pasar por la formación de las relaciones, los participantes fueron analizadas para la equivalencia entre las expresiones faciales, las imágenes abstractas y alimentos. La evaluación de la preferencia de alimentos se realizó al inicio y al final del experimento. El experimento consistió en tres diferentes grupos experimentales que diferían sólo en la cantidad de entrenamiento. Los alimentos equivalentes a las expresiones faciales de alegría y mujeres neutral sido objeto de evaluaciones más positivas que los alimentos equivalente a cara neutro masculino, sin embargo, los datos muestran una gran variabilidad. En el Experimento 2 expresiones faciales esquemáticos y nombres fictícios de alimentos fueron utilizados en un procedimiento de igualación a la muestra con retraso. La alimentación equivalente a la cara feliz se evaluó como más agradable y el equivalente a la cara triste se evaluó como menos agradable.

Palabras clave: Equivalencias de estímulos, transferencia de funcion, expresiones faciales, preferencias alimentarias.

The phenomenon of stimulus equivalence is of great interest because when stimuli are arbitrarily related to one another through a series of conditional discriminations, language-competent humans will readily demonstrate additional relations without further training. Stimulus equivalence, as defined by Sidman (Sidman \& Tailby, 1982), refers to derived conditional stimulus relations that show the properties of reflexivity, symmetry, and transitivity.

One particularly important aspect of stimulus equivalence is the derived transfer of functions through equivalence classes. After establishing stimulus equivalence classes, a function given to one member of a class may transfer to other members of that class (e.g., de Rose, McIlvane, Dube, Galpin, \& Stoddard, 1988; Dougher, Augustson, Markham, Greenway, \& Wulfert, 1994).
Experimental studies have simulated the acquisition of symbolic properties for abstract stimuli, in accordance with the mathematical definition of equivalence, thus allowing investigations of these properties with abstract stimuli and, less frequently, stimuli with pre-experimental meaning. Watt, Keenan, Barnes, and Cairns (1991) studied the formation of equivalence classes that comprised Catholic names and Protestant symbols in participants from Northern Ireland. The experimental training was opposite to the previous history of the participants, requiring that they included in the same class stimuli that had incompatible pre-experimental meanings. In the tests to verify equivalence formation, the participants had a tendency to respond according to their previous, more remote, and extensive history and not according to the recent and short history of their experimental 
training. Most of them still related the Protestant symbols to Protestant names rather than to the Catholic ones.

When experimental training did not compete with pre-experimental history, classes that comprised meaningful and abstract stimuli were readily formed, and functions of the meaningful stimuli transferred to the abstract stimuli. Y. Barnes-Holmes, Barnes-Holmes, Smeets, and Luciano (2004) trained matching-to-sample AB and $\mathrm{AC}$ relations to establish two three-member equivalence classes: A1-B1-C1 and A2-B2-C2. Afterward, the musical mood induction technique was used to establish a happy mood in the presence of one of the B stimuli (e.g., B1) and a sad mood in the presence of the other B stimulus (e.g., B2). The participants were subsequently tested for the emergence of these mood functions in response to the B stimuli and then tested for the transfer of these functions through derived equivalence relations in response to the $\mathrm{C}$ stimuli. Most of the participants showed the derived transfer of happy and sad mood functions through equivalence relations.

Another important study that investigated the transfer of functions using stimuli with pre-experimental meaning was reported by $\mathrm{D}$. Barnes-Holmes, Keane, Barnes-Holmes, and Smeets (2000). The general procedure was to match two neutral nonsense syllables, Vek and $\mathrm{Zid}$, to the negative word Cancer and positive word Holidays, respectively. The nonsense syllables were then matched to the product labels Brand $\mathrm{X}$ and Brand $\mathrm{Y}$. Later, the participants received two samples of the same cola drink, one labeled Brand $\mathrm{X}$ and the other labeled Brand $\mathrm{Y}$. According to D. Barnes-Holmes et al. (2000), "children that passed the test for equivalence class formation had a significant preference for the holidays-cola over the cancer-cola".

Bortoloti and de Rose $(2007,2009)$ also verified the transfer of functions of significant stimuli to abstract stimuli. The significant stimuli were pictures of human faces that expressed happiness, anger, or disgust (set A), whereas sets $\mathrm{B}, \mathrm{C}$, and $\mathrm{D}$ were formed by three abstract pictures each. The conditional relations $\mathrm{AB}, \mathrm{AC}$, and $\mathrm{CD}$ were taught for the experimental group.
When the equivalence criterion was reached, the participants were instructed to evaluate the abstract stimuli D1, D2, and D3 through a semantic differential. The control group who was not subjected to any training also evaluated the faces and abstract pictures. The properties of the facial expressions were transferred to the abstract stimuli that were equivalent to them. Thus, the study showed convergence between the evaluations of the facial expressions by the control group and evaluations of the $\mathrm{D}$ stimuli by the experimental group. Bortoloti and de Rose (2009) replicated these results and also found that the amount of transfer is inversely related to nodal distance. They also showed that delayed matching-to-sample training produces more transfer than simultaneous matching-to-sample training.

The results of Bortoloti and de Rose (2007, 2009) showed that pictures of facial emotional expressions imparted positive or negative evaluative functions on abstract stimuli that were equivalent to them. If similar transfer can also occur with non-arbitrary, already meaningful stimuli, then the stimulus equivalence paradigm could be used to alter the valence of and relative preference for such stimuli as foods. According to Birch (1999), food preferences are learned through experience with food and eating. Walsh and Kiviemi (2013) showed that the feelings that are associated with particular foods play a strong role in the choices that are made. The experiment investigated the causal relation between affective associations between fruits and future fruit consumption behavior in a priming test. Participants who were primed with positive affective associations with fruits were significantly more likely to select a fruit over a granola bar compared with participants in either the neutral or negative affective association conditions.

The present study investigated whether stimulus equivalence can alter food evaluations and food preferences. The stimulus equivalence paradigm is important for research on complex human behavior (Tourinho, 2012). The application of this procedure in the study of food preference may have important implications because it allows the emergence of untrained relations that are established through the transfer of stimulus 
functions. The aim of Experiment 1 was to form equivalence between a positive facial expression and a healthy food and verify whether this food might be valued more positively and also be more preferred in tests of food preferences that do not involve actual consumption of the foods.

\section{Experiment 1}

\section{Methods}

\section{Participants}

Seventy-one adolescents, aged 11-14 years, participated in the study. However, only 55 participants (23 girls and 32 boys) concluded the research. They were randomly divided into three experimental groups: 19 in the first group and 18 each in the second and third groups. The students received an educational toy as a reward for participation. The native language of the participants was Brazilian Portuguese, and all of the instructions were given in this language. The University of São Paulo ethics committee approved the research (reference Comitê de Ética em Pesquisas-Faculdade de Filosofia, Ciências e Letras de Ribeirão Preto [CEP-FFCLRP] no. 230/2005 - 2205.1.1850.59.4).

\section{Apparatus}

An Apple Macintosh computer (Mac OS 9.2.2) with Match to Sample (MTS) software (Dube \& Hiris, 1997) presented the stimuli and recorded the data. Individual sessions were conducted in a room at the participant's school. Each session lasted approximately $30 \mathrm{~min}$. Three to five sessions were needed to complete the experiment. Photos of human expressions (Pictures of Facial Affect; Ekman, 1993), abstract line drawings (black lines over a white background), and written names of healthy foods (e.g., fruits like banana, orange, pineapple, and peach and vegetables like chayote, pumpkin, broccoli, and carrot) were used as stimuli (Figure 1) and presented in $5^{\prime} 5 \mathrm{~cm}$ windows on the computer monitor. The windows were located at the center, upper left, upper right, lower left, and lower right of the screen. A preference scale and food preference test were used to evaluate food preferences.

\section{Emotion Faces Abstract Stimulus}

Food Names

A1
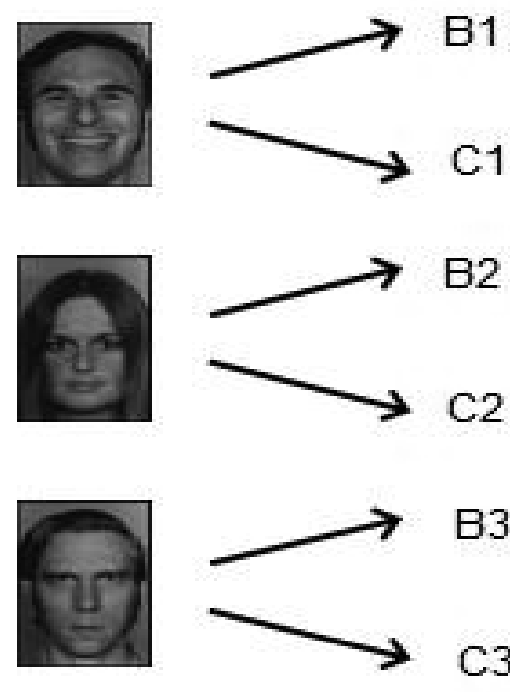

B3

A3

$\mathrm{C} 3$
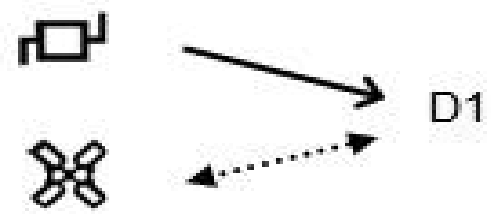

FOOD X
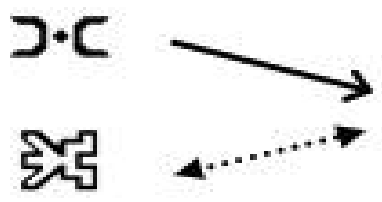

D2 FOOD Y
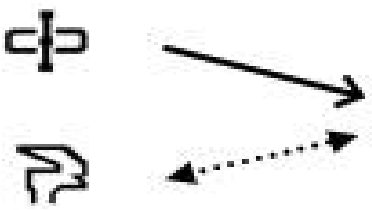

D3 FOOD Z

Figure 1. Schematic representation of the trained relations (solid lines) and tested relations (dashed lines) in Experiment 1. 
A preference scale that consisted of 50 names of foods was used for an initial selection of food names for each child. Beside each name was a 5-point scale of facial expressions (happy to sad: 2 to -2 ). For example, if the child did not like apples, then he/she should mark the interval of the sad expression (-2). But if he/she considered the food to be pleasant or tasty, the space that indicated the happy expression (2) should be chosen. If the child judged this food as neutral, then he/she should mark the interval of the neutral expression (0). If the food was considered "slightly unpleasant" (-1) or "slightly pleasant" (1), then the space between the neutral expression and sad expression or between the neutral expression and the happy expression, respectively, should be marked.

The preference scale data were used in a food preference test, in which the criterion of choosing the items was based on the interval attributed to each food (2 to -2$)$. Ten foods that were valued as neutral $(0)$ on the preference scale were selected for the preference test. Obtaining a sufficient number of foods that were evaluated as neutral was sometimes impossible. Therefore, foods that were in the adjacent intervals (1 or -1$)$ were used to complete the preference test. Each trial in this test displayed two food names on opposite sides of the lower section of the monitor (e.g., banana on the left and apple on the right). The preference test comprised 90 trials, and the 10 foods were randomly balanced (each food was presented with the other on the screen; therefore $10^{\prime}$ 9). Thus, each food appeared on the screen 18 times, nine times on the right side of the screen and nine times on the left. The participant told the experimenter which was the preferred food, and the experimenter clicked this food name with the mouse. Three foods that were within a central range of preference in this test were selected to be the stimuli in the training phase.

Three pictures of facial emotional expressions were used for all of the children: a male's expression of happiness and two neutral expressions (one from a male and another from a female; see Figure 1).

\section{General Procedure}

The experimental sessions comprised blocks of conditional discrimination trials. Each trial began with the presentation of the sample stimulus in the center window. The participants moved the mouse to place the arrow-shaped cursor within the sample window and clicked the mouse button, followed by the presentation of three comparison stimuli in three of the outer windows. The sample remained present on the screen. The participant then selected one of the comparison stimuli, placing the cursor within its window and clicking the mouse button. Correct selections were followed by an animated picture on the screen (moving multicolored stars), and incorrect selections resulted in a black screen. The positions of correct selections were balanced across trials.

To demonstrate the correct response, the sample was first presented at the beginning of the block, with the correct comparison only, twice for each sample-comparison relation. In the sequence, the sample stimulus was presented with two comparison stimuli, comprising four trials of each sample-comparison relation. Finally, the sample stimulus was presented with three comparison stimuli, comprising six trials of each relation for a total of 36 trials. To advance to the next block, the participant should make at least 35 correct responses. Each block of the training phase comprised 36 trails. If the criterion was not attained, then the next block had 18 trials, and the mastery criterion was at least 17 correct responses. If the criterion was still not attained, then the block was repeated. If the participant failed again, then he/she was excluded from the experiment. This criterion was used only in the training phase.

The experimental groups differed in the number of blocks of training after attaining the criterion (overtraining). The first group did not receive overtraining, whereas the second group had one block of overtraining (36 trials), and the third group had five blocks of overtraining (180 trials). 


\section{Sequence of Experimental Conditions}

Initial Tests. For the initial tests, the preference scale and food preference test consisted of Pretraining and Phases 1-4.

1. Pretraining. The objective of this phase was to teach the procedure of simultaneous matching-to-sample in a block that comprised 30 trials. The stimuli $\left(\mathrm{X}_{1}\right.$-parrot, $\mathrm{X}_{2}$-butterfly, $\mathrm{X}_{3}$-dog, $\mathrm{Y}_{1}$-blue, $\mathrm{Y}_{2}$-yellow, and $\mathrm{Y}_{3}$ brown) were different from the stimuli used in the later phases. In the first trial, each participant was instructed to click the mouse button on the sample stimulus $X_{1}$ and then select the correct stimuli $Y_{1}$. Afterward, the sample stimulus $X_{2}$ and correct comparison $Y_{2}$ and finally $X_{3}$ and $Y_{3}$ appeared. The other trials displayed the sample stimulus and three comparisons. The criterion to complete pretraining was $100 \%$ correct responses, and the block was repeated until this criterion was attained.

2. Phase 1. For conditional discrimination training, the conditional discriminations $\mathrm{AB}$, $\mathrm{AC}$, and $\mathrm{BD}$ were trained. The $\mathrm{AB}$ conditional discrimination was trained first (see General Procedure). If the criterion was not achieved in a block of 36 trials, then a block of $18 \mathrm{AB}$ trials followed. If the block was presented twice and the criterion was not achieved, then the participant was excluded from the experiment. After the criterion was reached, the AC relation was trained, followed by training the relation $\mathrm{BD}$.

3. Phase 2. To achieve a cumulative baseline, this phase mixed the trials of all of the previously trained relations $(\mathrm{A} 1 \mathrm{~B} 1, \mathrm{~A} 2 \mathrm{~B} 2$, A3B3, A1C1, A2C2, A3C3, B1D1, B2D2, and B3D3; see Figure 1). This block was composed of 36 counterbalanced trials, four times each pair.

4. Phase 3. For overtraining, the block of 36 trials of cumulative baseline was repeated after the criterion was attained, once for Experimental Group 2 and five times for Experimental Group 3.

5. Phase 4. The $\mathrm{CD} / \mathrm{DC}$ equivalence test began with a message (in Portuguese) that ap- peared on the screen, translated as: "From now on the computer will not signal if your choices are correct or incorrect. Please continue." In the test phase, 18 trials were presented to evaluate whether the responses were consistent with the formation of an equivalence class. The criterion for equivalence class formation was the achievement of 16 trials.

Final Tests. For the final tests, the preference scale and food preference test were repeated.

\section{Results and Discussion}

Thirty five participants demonstrated equivalence (63.6\%): $47.4 \%$ in the Group 1, $61 \%$ in Group 2, and 83.3\% in Group 3. The difference in the amount of training between the experimental groups showed that overtrained participants performed better in the stimulus equivalence test. This result is consistent with previous studies that reported increases in retention as a result of increases in the amount of overtraining (Brown, 1970; Driskell, Willis, \& Copper, 1992), suggesting that overtraining is an effective way to improve performance (Driskell et al., 1992; Schendel \& Hagman, 1982). Examination of the data of the participants who demonstrated equivalence (Figure 2) revealed that Group 1 had the largest proportion of participants $(66.6 \%)$ who improved their evaluation of the food that was equivalent to the happy face (A1) in both tests. In Group 2, 18\% of the participants more positively evaluated food that was trained with a happy face in both tests. In Group 3, 46.6\% of the participants improved their evaluation of the food that was equivalent to the happy face in both tests. However, evaluations of the food that was equivalent to the neutral face also improved. To determine differences between groups, statistical analyses were performed. 


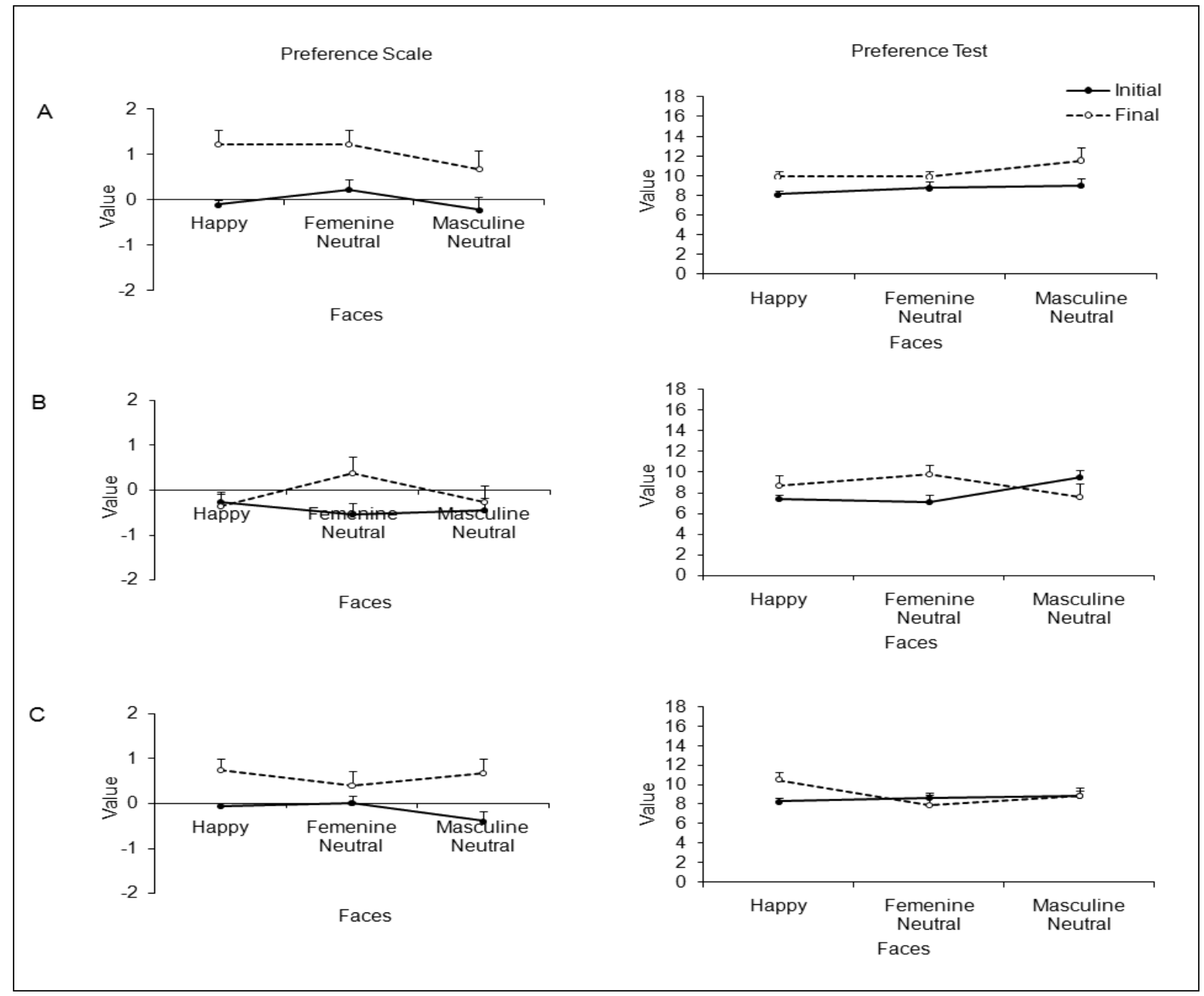

Figure 2. Average of the initial and final preference scales (scored 2 to -2 ) and preference tests (scored 0 to 18) of the foods trained with happy, female neutral, and male neutral faces in the experimental groups that showed equivalence. $\mathrm{A}, \mathrm{B}$, and $\mathrm{C}$ represent the experimental Groups 1, 2, and 3, respectively. The bars show the standard error of the mean (SEM).

With the objective of determining whether the data obtained for the preference scale and in the food preference test were correlated, the Spearman correlation coefficient was used, with a significance level of $p<.05$. This procedure was performed using SAS 9.1 software. The initial assessments of the foods indicated a very weak correlation between the preference scale and food preference test $(r=.17)$. The final assessments indicated a moderate correlation $(r=.43)$. Separation of the data according to foods that were related to faces within the three groups indicated a positive correlation between the preference scale and food preference test only in the group who achieved equivalence in the following foods and groups of training: food trained with the male neutral face in Group $1(r$ $=.64$ ) and food trained with the female neutral face in Group $2(r=.72)$.

The preference scale results between the initial and final assessments were compared using the nonparametric Cochran $Q$ test, with a significance level of $5 \%$, which was performed using SAS 9.0 software. Significant differences were found only for the results of the participants who achieved equivalence: food trained with a happy face in Group $1(p=.002)$ and Group $3(p=.02)$, food trained with a female neutral face in Group $2(p=.01)$, and food trained with a male neutral face in Group $3(p=.01)$. 
To compare the initial and final food preference test results, we used a linear mixed effects model with SAS 9.0 software. Significant differences $(p<.05)$ were found only in the group who formed equivalence with the food trained with a male neutral face in Group 1, food trained with a female neutral face in Group 2, and food trained with a happy face in Group 3. Improvements were observed in the final evaluations of these foods.

Therefore, the assessment of foods that were paired with a happy face improved on the preference scale in Groups 1 and 3 and in the food preference test in Group 3. Group 2 rated food that was paired with a neutral female face significantly better in both tests. Lastly, the assessment of foods that were paired with a neutral male face improved in the food preference test in Group 1 and on the preference scale in Group 3.

A larger amount of training relations likely provided greater discrimination of the trained relations because the foods that were related to a happy face received higher ratings on both instruments in Group 3. However, a methodological review is necessary to clarify why the food trained with a neutral female face in Group 2 was also rated higher on both instruments. One possibility may be to reduce the amount of trained stimuli. For example, one group would learn only the relations between the happy face and food, and the other groups would learn relations with the female neutral face and male neutral face.

The present study used actual faces as stimuli that are potentially equivalent to names of actual foods. Because real faces are very complex stimuli, specific features of the faces, in addition to their emotional expressions, may have exerted some control and interfered with the transfer of positive functions from the happy expression. Some studies on the recognition of facial expressions used schematic facial expressions to enhance discrimination of the emotion (e.g., Leppänen \& Hietanen, 2004; Öhman, Lundqvist, \& Esteves, 2001). Despite their obvious simplicity, facial schematic expressions appear to effectively convey anger, happiness, sadness, and emotional neutrality (e.g., Fox et al., 2000; Öhman et al., 2001; White, 1995).
In two studies by Bortoloti and de Rose (2007, 2009), the participants formed one class that comprised a happy face, one class that comprised an angry face, and one class that comprised a neutral face. The contrast with a negatively valued face may have improved the positive value of the happy face. In the present study, the happy face was contrasted with two neutral faces (one female and one male). We avoided the use of angry or disgusted faces because it might be unethical to make actual foods equivalent to these negatively valued stimuli.

Bortoloti and de Rose (2009) also showed that the transfer of functions is higher when stimulus relations that are conducive to equivalence are established with a delayed matching procedure than when they are established with simultaneous matching, such as in the present study (see also Arntzen, 2006; Vaidya \& Smith, 2006). Therefore, a second study was conducted to evaluate the transfer of functions from schematic faces to fictitious foods after a delayed matching-to-sample procedure yielded the formation of equivalence classes.

\section{Experiment 2}

\section{Methods}

\section{Participants}

Sixty-three adolescents from a public school, 11-14 years of age, participated in the study. However, only 36 participants concluded the experiment (18 boys and 18 girls). They received an educational toy at the end of the study for their participation.

\section{Apparatus}

The setting and apparatus were the same as in Experiment 1. The stimuli were schematic expressions of happiness, neutrality, and sadness, arbitrary stimuli of the MTS software, and fictitious names of foods (Capira, Fulito, and Piteba). The preference scale from Experiment 1 was used to evaluate the fictitious names of foods, but actual faces were replaced by schematic expressions. The participants read printed 
instructions that asked them to imagine that they traveled to another planet where they went to a restaurant that had three options of food: capira, fulito, and piteba (these names are presumably meaningless in Portuguese, the language spoken by the participants). They were asked to evaluate these foods according to the impression they had of their names. Capira, Fulito, and Piteba were consistently paired with the happy, neutral, and sad expressions, respectively, and were not counterbalanced because these were fictitious names that supposedly did not have a function for the participants.

\section{Procedure}

A delayed matching-to-sample procedure was used to train conditional discriminations (Figure 3). A 1 s delay occurred between the offset of the sample stimulus and onset of the comparison array. The procedure was the same as for Group 2 in Experiment 1 (with one block of overtraining) to ensure that a large number of participants would form stimulus equivalence and discriminative relations would be trained faster compared with Group 3 in Experiment 1.

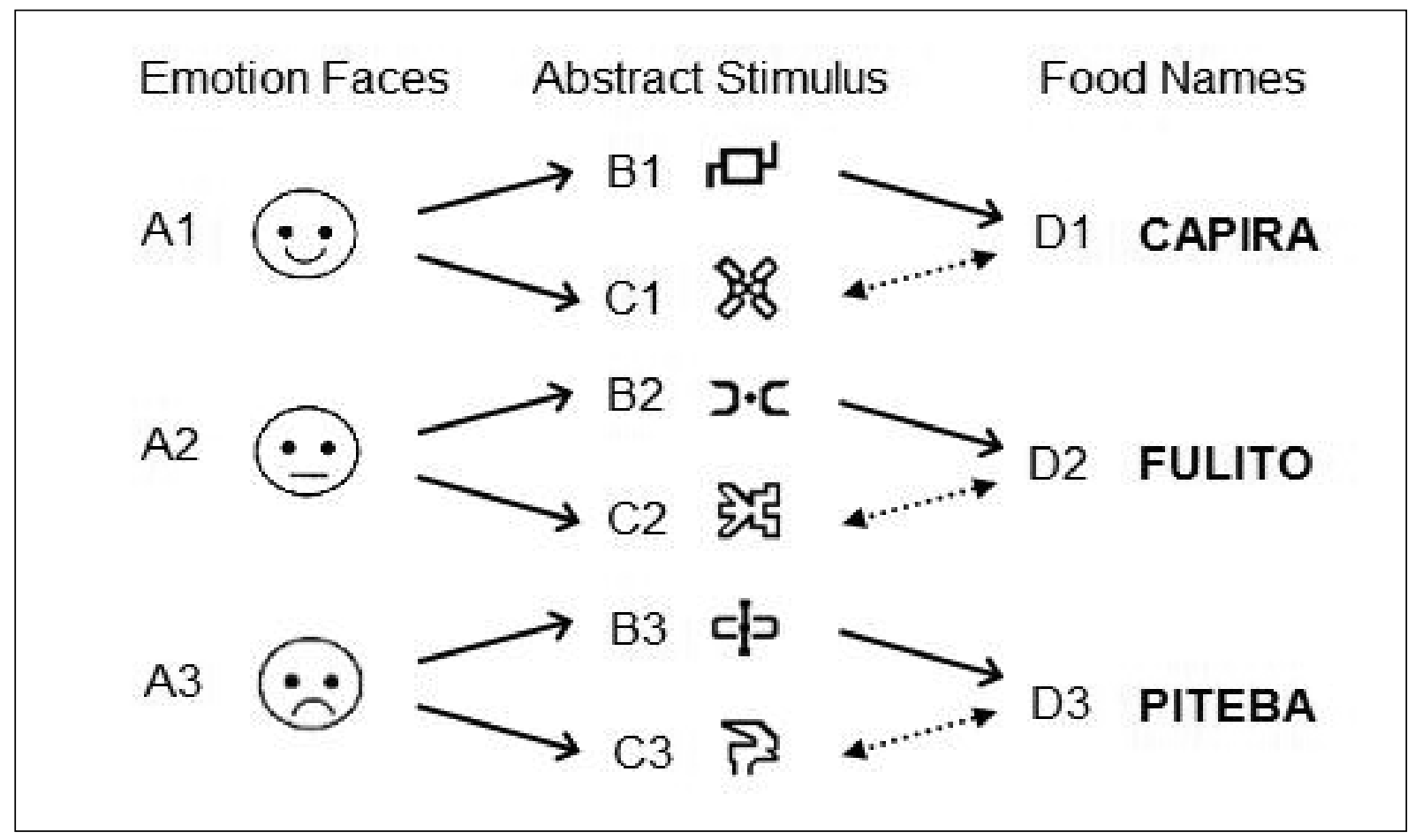

Figure 3. Schematic representation of the trained relations (solid lines) and tested relations (dashed lines) in Experiment 2.

\section{Results and Discussion}

The preference scale data were divided into two different groups, one that showed equivalence class formation and one that did not. The data were analyzed using the nonparametric Cochran's $Q$ test, with a significance level of $5 \%$. The statistical analyses were performed using SAS 9.0 software to compare differences between the initial and final scales. The statistical analysis showed no significant difference between the initial and final preference scales in the group that did not form equivalence classes. However, a significant effect of was found in the group that achieved equivalence in relation to the Capira and Piteba foods.

Twenty-five participants demonstrated equivalence (69.4\%). Among these participants, $48 \%$ improved the final evaluations of the food that was equivalent to the happy face (Capira), $36 \%$ maintained approximately the same evaluation of the food that was equivalent to the neutral face (Fulito), and $68 \%$ considerably decreased the evaluation of the food that was equivalent 
to the sad face (Piteba; Figure 4). Therefore, in this experiment, the transfer of the properties of the faces appeared to occur in a more consistent way, especially with the happy and sad faces. However, we cannot draw conclusions about which factors influenced this transfer because to improve the probability of replicating the results of Bortoloti and de Rose (2009), three variables were altered from the procedure in Experiment 1 , in which schematic faces and fictitious names of foods were used instead of actual faces and names of foods, and the matching-to-sample procedure was changed from simultaneous to delayed. Each of these variables or a combination of them may have contributed to the significant effects found in this study.

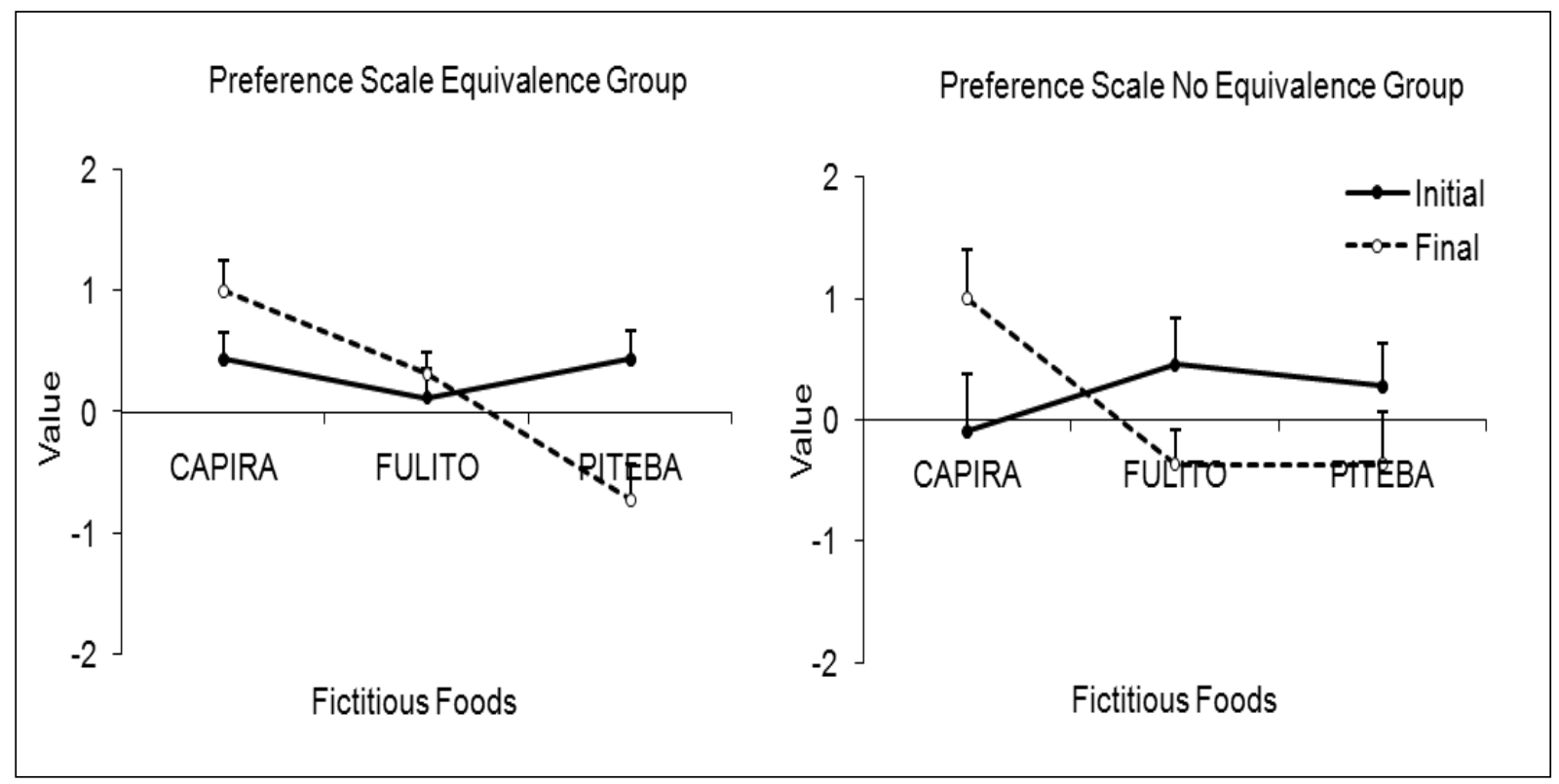

Figure 4. Average of the initial and final preference scales (scored 2 to -2) of the fictitious foods capira, fulito, and piteba for participants who showed equivalence and those who did not. The bars show the standard error of the mean (SEM).

\section{Conclusion}

Experiment 1 established equivalence classes that consisted of happy or neutral faces, arbitrary stimuli, and food names. Foods that were equivalent to the happy faces were generally evaluated more positively by the participants who formed equivalence, but a more positive evaluation was also found for foods that were equivalent to neutral faces. Therefore, we cannot attribute the improved valence to the transfer of functions between equivalent stimuli. To unambiguously demonstrate the improved valence of foods that were equivalent to happy faces, Experiment 2 used schematic faces and fictitious names of foods instead of actual ones and a delayed matching-to-sample procedure. The results showed that the fictitious food that was equivalent to the happy face was evaluated more positively compared with the pre-test. The food that was equivalent to the sad face was evaluated more negatively, whereas the evaluation of the food that was equivalent to the neutral face did not change.

The procedural changes in Experiment 2 made that experiment more similar to those of Bortoloti and de Rose $(2007,2009)$. These studies established arbitrary pictures as stimuli that were equivalent to happy, angry, and neutral faces. Experiment 2 in the present study established equivalence classes between happy, sad, and neutral faces, arbitrary pictures, and arbitrary names that were presented to the children as names of imaginary foods. Unsurprising is that more clear and consistent results were seen in the transfer of functions to arbitrary names than 
to actual names of foods because the arbitrary names were free of the confounding factors that would be associated with a pre-experimental history.

The present study was the first to attempt to modify food preference using a stimulus equivalence paradigm. According to Popkin, Adair, and $\mathrm{Ng}$ (2012), over the past several decades a dramatic shift has been seen in the way the entire globe eats, drinks, and moves, which clashes with human biology to create major shifts in body composition. These authors also reported that being overweight and obese afflicted nearly 1.5 billion adults worldwide in 2008, and an estimated 2.16 billion adults will be overweight and 1.12 billion will be obese in 2030 . To prevent future problems and provide for those with nutrition-related noncommunicable diseases (e.g., obesity, diabetes, and cancer, among others), finding ways to improve dietary patterns globally is necessary (Popkin et al., 2012). The technology developed by the stimulus equivalence paradigm may provide a possibility of intervening in this worldwide problem to help increase the preference for healthy foods.

\section{References}

Arntzen, E. (2006). Delayed matching to sample: Probability of responding in accord with equivalence as a function of different delays. The Psychological Record, 56(1), 135-167.

Barnes-Holmes, D., Keane, J., Barnes-Holmes, Y., $\&$ Smeets, P. M. (2000). A derived transfer of emotive functions as a means of establishing differential preferences for soft drinks. The Psychological Record, 50(3), 493-511.

Barnes-Holmes, Y., Barnes-Holmes, D., Smeets, P. M., \& Luciano, C. (2004). A derived transfer of mood functions through equivalence relations. The Psychological Record, 54(1), 95-113.

Birch, L. L. (1999). Development of food preferences. Annual Review of Nutrition, 19, 41-62. doi:10.1146/annurev.nutr.19.1.41

Bortoloti, R., \& de Rose, J. C. (2007). Medida do grau de relacionamento entre estímulos equivalentes. Psicologia: Reflexão e Crítica, 20, 252-258. doi:http://dx.doi.org/10.1590/S010279722007000200011
Bortoloti, R., \& de Rose, J. C. (2009). Assessment of the relatedness of equivalent stimuli through a semantic differential. The Psychological Record, 59(4), 563-590.

Brown, A. L. (1970). Transfer performance in children's oddity learning as a function of dimensional preference, shift paradigm and overtraining. Journal of Experimental Child Psychology, 9(3), 307-319.

De Rose, J. C., McIlvane, W. J., Dube, W. V., Galpin, V. C., \& Stoddard, L. T. (1988). Emergent simple discrimination established by indirect relation to differential consequences. Journal of the Experimental Analysis of Behavior, 50(1), 1-20. doi:10.1901/jeab.1988.50-1.

Dougher, M. J., Augustson, E., Markham, M. R., Greenway, D. E., \& Wulfert, E. (1994). The transfer of respondent eliciting and extinction functions through stimulus equivalence classes. Journal of the Experimental Analysis of Behavior, 62(3), 331-351. doi:10.1901/jeab.1994.62-331.

Driskell, J. E., Willis, R. P., \& Copper, C. (1992). Effect of overlearning on retention. Journal of Applied Psychology, 77(5), 615-622.

Dube, W. V., \& Hiris, J. (1997). Match to sample program (Version 11.1.3) [Computer software]. Waltham, MA: E. K. Shriver Center for Mental Retardation.

Ekman, P. (2003). Pictures of Facial Affect (POFA) [CD-ROM]. Retrieved from www.paulekman. com

Fox, E., Lester, V., Russo, R., Bowles, R. J., Pichler, A., \& Dutton, K. (2000). Facial expressions of emotions: Are angry faces detected more efficiently? Cognition and Emotion, 14, 61-92. doi:10.1080/026999300378996.

Leppänen, J. M., \& Hietanen, J. K. (2004). Positive facial expressions are recognized faster than negative facial expressions, but why? Psychological Research, 69, 22-29. doi:10.1007/ s00426-003-0157-2

Öhman, A., Lundqvist, D., \& Esteves, F. (2001). The face in the Crowd Revisited: A threat advantage with schematic stimuli. Journal of Personality and Social Psychology, 80(3), 381-396. doi:10.1037//0022-3514.80.3.381

Popkin, B. M., Adair, L. S., \& Ng, S. W. (2012). Global nutrition transition and the pandemic of obesity in developing countries. Nutrition Reviews, 70(1), 3-21. doi:10.1111/j.17534887.2011.00456.x 
Schendel, J. D., \& Hagman, J. D. (1982). On sustaining procedural skills over a prolonged retention interval. Journal of Applied Psychology, 67(5), 605-610.

Sidman, M., \& Tailby, W. (1982). Conditional discrimination vs. matching to sample. An expansion of the testing paradigm. Journal of the Experimental Analysis of Behavior, 37(1), 5-22. doi:10.1901/jeab.1982.37-5

Tourinho, E. Z. (2012). Analogia, metáforas e cognições - Comentários a partir do artigo de Ruiz e Luciano. Acta Comportamentalia, 20(4), 32-37.

Vaidya, M., \& Smith, K. N. (2006). Delayed matching-to-sample training facilitates derived relational responding. Experimental Analysis of $\mathrm{Hu}$ man Behavior Bulletin, 24, 9-16.

Walsh, E. M., \& Kiviniemi, M. T. (2013). Changing how I feel about the food: Experimentally manipulated affective associations with fruits change fruit choice behaviors. Journal of $\mathrm{Be}$ havioral Medicine. Advance online publication. doi:10.1007/s10865-012-9490-5
Watt, A., Keenan, M., Barnes, D., \& Cairns, E. (1991). Social categorization and stimulus equivalence. Psychological Record, 41, 33-50.

White, M. (1995). Preattentive analysis of facial expressions. Cognition and Emotion, 9, 439-460. doi:10.1080/02699939508408975

Received: May, 14, 2013

$1^{\text {st }}$ revision: October, 15,2013

$2^{\text {nd }}$ revision: December, 02, 2013

Accepted: December, 03, 2013 